\title{
A Distributed National Stored Collection: Testing the Possibilities
}

\author{
Paul Genoni \\ School of Media, Culture and Creative Arts \\ Curtin University \\ GPO Box U1987, Perth 6845
}

p.genoni@ curtin.edu.au

\begin{abstract}
This paper reports on a study of the holdings of a single discipline (Design) by a single institution (RMIT University Library) in order to test for the possibility of a form of distributed national storage in Australia. The study was undertaken using OCLC Collection Analysis software and the WorldCat database. The collection of RMIT University Library is compared with two 'groups' of libraries, the first consisting of seven Victorian academic library collections, and the second of three Melbourne-based non-academic libraries considered to have strong Design collections. Conclusions indicate that for this discipline a form of distributed storage is already in place, with the RMIT University Library collection making a considerable and complementary contribution to the state wide holdings.
\end{abstract}

Keywords Print storage; Collection overlap; OCLC Collection Analysis; National repository; Australia

\section{Introduction}

As libraries struggle with the rising costs of print storage they are inevitably seeking ways of reducing this ongoing impost. Various forms of shared or collaborative storage have emerged as a possible solution, and these are increasingly based on some form of national strategy that ensures long-term retention of individual titles while allowing libraries to de-duplicate local collections. Australian research libraries, deterred by issues related to access and up-front costs, have shown a disinclination to create a large, centralised national repository. Another option might be found, however, in a form of distributed, library-based storage such as that adopted in the United Kingdom.

The purpose of this paper is to describe a preliminary examination of the possibilities for a similar response in Australia. It is based on an analysis of the current situation regarding one Australian academic library (RMIT University), and one discipline collection (Design).

\section{Background}


In recent decades many Australian university libraries have needed to reassess the future of their print collecting and storage as they have adapted to the both the influx of digital content and the shift to digital modes of learning and research. In particular libraries have been under considerable pressure to release storage space for other uses associated with networked learning while they continue to acquire print material.

Some mid-size or smaller Australian university libraries have responded to the lack of storage space by adopting "steady-state" collections whereby the volume of incoming items is matched by the volume of outgoing (discarded) items (Genoni, 2008). Other librariesparticularly those supporting universities with a high-intensity research focus - have elected to retain a high proportion of their print materials and have adopted other strategies in order to reduce the collection footprint at their primary library site. These solutions have usually relied upon sending items to independently or jointly managed high-density, off-site storage, and more recently several libraries (for example Macquarie University and University of Technology Sydney) have opted for Automatic Storage and Retrieval Systems (ASRS) that allow for high density on-site retention, albeit with some reduction in access.

Despite the developments in ASRS technology many libraries will continue to look for offsite storage as the most cost-effective means of long-term print management. This has resulted in a considerable amount of discussion in the literature over several decades on the forms of shared or collaborative storage that might result. While the extent and range of this literature has recently been traced elsewhere (Genoni, 2013), two strands from that literature are worth foregrounding as being particularly relevant to this paper.

Firstly, the benefits of print storage could be optimised from various economies of scale associated with building and management. This is true whether it be several locally affiliated libraries deciding to create a storage facility to deal with the overflow of low use items; or a more broadly based regional grouping creating an independently managed storage/repository facility and collection and actively encouraging contributing libraries to de-duplicate based on undertakings for long term retention. In the Australian context the Universities' Research Repository South Australia is an example of the former, and Victoria's CARM Centre Collection an example of the latter. It is apparent that with developments in digital discovery and delivery services that there has been a move towards creating shared stores or repositories on an ever broader geographic scale. This is particularly evident in the United States, where local and state based storage services are now moving towards implementing a series of mega-regional repositories networked in order to provide national coverage (Kieft and Payne, 2010; Kieft and Payne, 2012; Lavoie, Malpas and Shipengrover. 2012).

Secondly, there are good reasons why a nation that is engaged in the reduction of its print book stock should do so in a planned and managed environment. This is important in order to both protect research capacity and to ensure that scholars (and libraries) are confident in relinquishing local ownership. The benefits of a managed approach include ensuring that there are commitments with regard to storage conditions, security and long-term retention; the consistent application of best-practice discovery and delivery services; providing for the 
protection of last copies; and ensuring that costs for the maintenance of a storage network are fairly distributed.

These developments in the theory and practice of print storage have led (or should lead) to a reconsideration of the situation in Australia, where progress towards some form of coordinated national response to the print storage "crisis" has been hesitant and is in danger of falling behind the initiatives in evidence elsewhere.

\section{National Repositories}

National approaches to print storage are not a recent innovation. European countries in particular, many with the advantage of a comparatively compact geographic area, moved in this direction as early as the 1980s. Some European countries that have implemented a national repository approach to guarantee secure retention of print material include Finland, France, Germany and Estonia (Vattulainen, 2004; Saarti and Vattulainen, 2013), and in the southern hemisphere New Zealand has recently taken a similar move (Renwick, 2013). These national repositories differ in terms of their management, inclusiveness and operational details, but in essence they all attempt to firstly, ensure last copy retention under favourable conditions for all titles within the national collection; and secondly, deliver benefits to all libraries in terms of reducing storage costs by withdrawing duplicated titles from local collections if they wish to do so.

The United Kingdom has chosen a somewhat different solution. After commissioning a major report (CHEMS Consulting, 2005) that considered several possibilities for creating a distributed network of stores, the British Library in conjunction with other major research libraries resolved in favour of the United Kingdom Research Reserve (UKRR) a distributed storage system based on the holdings of the British Library and supported by a network of existing research library collections and buildings. In its initial phases the UKRR has focused on ensuring the permanent retention of a specified number of copies of journals and encouraged deduplication (Boyle and Brown, 2010; Shorley, 2008). As at 2012 the UKRR has processed the removal of more than 60,000 metres of low-use print journals that had occupied some 9,249 square metres of floorspace. The resulting savings for participating libraries amount to over $£ 18 \mathrm{~m}$ in capital savings, and more than $£ 5 \mathrm{~m}$ in recurrent management costs (Yang, 2013). The UKRR is currently establishing a business model for future operations that will carry it beyond the phase covered by start-up funding, and it is envisaged that it will eventually be extended to include monographs.

In the United States the situation with regard to a national approach to print storage has been dictated by both the extensive geography involved and by a higher education system that has been historically funded by states. As a result the shared stores and repositories that have developed have often been dictated by state boundaries. In recent years, however, several bodies with supraregional responsibilities including OCLC and the Center for Research Libraries have engaged in discussions and research regarding the prospects for creating a network of regional repositories that will constitute a de facto national repository (Kieft and Reilly, 2009; Kieft and Payne, 2010). As Kieft and Reilly (2012) have recently predicted 
about the future of shared print storage in the US, "the current regional and ad hoc shared print initiatives are likely to be transformed by increased scale, scope, connectivity, and costsharing" (143). The increases in scale and scope include extending the basis for collaborative print storage beyond the traditional academic and research library sector and building a more inclusive base that encompasses public and special libraries (Kieft and Reilly, 2009).

A recently established national repository service is that implemented by eight New Zealand universities represented by the Council of New Zealand University Librarians in 2011 (Renwick, 2013). After a decade of discussion and planning government funding was eventually obtained to allow the creation of a distributed network of repositories managed by a consortium owned by Universities New Zealand. Ownership of items in the repository is ceded to the consortium, and as with the UKRR the initial focus is on journals with plans to extend the service to monographs at a later stage.

\section{Australia}

Australia has a history of theorising (and partly implementing) the benefits of collaborative collection management. In the 1980s in particular the concept of the Distributed National Collection (DNC) gained considerable purchase. The DNC was fundamentally a collaborative approach to managing the nation's print-based research and information infrastructure, with both research and non-research libraries having a role to play. Its main activities were to be focused on collection development, with a fully implemented DNC potentially having individual libraries taking on particular responsibilities with regard to developing subject based collections (Wainwright, 1991). In such a system the role of storage and retention of subject material would also fall to the libraries who assumed the responsibility for collecting. For a number of reasons, but partly as a result the inadequate infrastructure for mapping and recording both collection strengths and the frequency of overlap between collections, the DNC did not eventuate as envisaged (Genoni, 2001).

After the DNC failed to become established the focus within the Council of Australian University Librarians (CAUL) shifted from collaborative purchasing to the prospect of collaborative storage in the form of a possible National Collaborative Library Storage Strategy. This response has been fitfully supported within CAUL for over a decade without producing any broad consensus or outcome (Genoni, 2007). In the absence of a national strategy the leadership with regard to shared storage has been taken by the Victorian-based CARM Centre. CARM operates as both a repository, with ownership of items ceded to the CARM Centre operator CAVAL and the resulting collection (CARM Collection) deduplicated; and as a store, with libraries leasing space to house their low-use materials of which they retain ownership (O'Connor, 2004; Wright, Jilovsky and Anderson, 2012; Jilovsky, 2013). CARM remains, however, a largely regional service, with nine of the eleven member universities being based in Victoria. It is also notable that the recent extension for the CARM Centre (CARM2) depended on a business model based on the leasing of space for storage rather than the further development of the repository-style CARM Collection (Wright, Jilovsky and Anderson, 2012). This shift in focus within Australia in the post-DNC era is in line with developments in cooperative collection management of print elsewhere, 
which has seen the focus shift from the beginning of the life-cycle (selection and acquisition) to the end (storage and disposal) (Clement, 2012).

The National and State Libraries Australasia (NSLA) (2010) consortium has also agreed to implement a "distributed repository" as a means of collaboratively managing low use print material in the collections of national, state and territory libraries. In March 2012 a memorandum of understanding was signed endorsing a project that aims to "build on specialist collections, assemble complete runs of journals, release storage space, and enhance opportunities for collecting state heritage material" (http://www.nsla.org.au/projects/collaborative-collections). The initial focus of the project appears to be on reducing duplicate journals, but the intention is that monographs may also be transferred between libraries in accordance with existing collection strengths.

\section{The study}

This study was based on an assumption that Australian libraries might continue to favour a national system that is based on distributed storage rather than a centralised repository (be it a single repository or a network of regional repositories). This has the advantage of being considerably cheaper in a start-up phase as it requires no new building or large-scale transfer of material. Libraries can still choose to de-duplicate local collections according to their own priorities. The disadvantages when compared to a repository model is that there is less consistency in terms of physical management or intellectual access, and discovery and delivery services may vary considerably across the network. It is therefore less likely to encourage deduplication and the system-wide costs for storage are likely to remain higher.

It is also the case that within Australia a distributed system of storage would differ from that in the United Kingdom. The UK has the advantage of a national library and a higher education system that have worked together more closely than is the case in Australia, and the National Library of Australia lacks the universal collection strength that allows the British Library to play the foundation role in the UKRR.

In such circumstances the onus may fall to individual libraries to nominate a role within a national system calling upon the areas of excellence within their collections. This is in effect a variation of the DNC approach, with a library electing to both collect and retain (store) print items within a particular subject. To test this approach, and in particular how it can be supported by currently available databases and software, a test was conducted on the collection of the Library of RMIT University.

RMIT University and its Library are located centrally in Melbourne and within close proximity of some of the state's largest collections, including those of the State Library of Victoria and University of Melbourne. It is also a collection that is severely constrained by the current building envelope and has little scope for expanding storage space (Anderson, 2013). The Library has, however, been putting considerable effort into developing selected areas of the collection, particularly in the subjects of design and technology. With this in mind it was decided to focus on the discipline of Design for this research, and to draw data from OCLC's WorldCat using their Collection Analysis software. The Collection Analysis 
software is designed to enable libraries to undertake collection comparisons with similar libraries or groups of libraries, and data can be mined on the basis of subject and to the level of individual titles. WorldCat and the Collection Analysis software have been used previously for overlap studies based on Australian research library collections and found to provide a level of utility not available from other databases, such as Libraries Australia (Genoni and Wright, 2010; Genoni and Wright, 2011). It should be noted that as with all studies drawing upon catalogue holdings the accuracy of results will be affected by the completeness and currency of the data.

OCLC have recently developed additional features to enhance the usefulness of WorldCat bibliographic data to support collaborative print storage. In January 2013 OCLC launched a Shared Print Management Program in order to support the "growing number of regional efforts ... to consolidate and preserve print collections among multiple libraries" The OCLC program is based around leveraging the WorldCat data "because of its global reach and integration with the workflow of most libraries that participate in shared print programs" (www.oclc.org/productworks/shared-print-management.htm).

\section{Methodology}

A feature of the OCLC Collection Analysis software is that it takes a Conspectus approach to subject information and classification. There are 32 Divisions (broad discipline classifications) within the Conspectus, which can be mapped to Dewey Decimal, Library of Congress, and National Library of Medicine classification schemes. The 32 Divisions are in turn divided into approximately 500 Categories and 7000 Subjects.

RMIT University includes a School of Architecture and Design, which incorporates teaching in architecture; fashion; industrial design; interior design; and landscape architecture. The research activity in this area is based on the Centre for Design (created in 1989), which currently supports research with a focus on environmentally sustainable design and urban systems. Key research areas include life cycle assessment; sustainable products and packaging; and sustainable building innovation.

For the purpose of this study the Design collection was taken to be all of those items classified under the two Conspectus Categories; "Decorative Arts, Applied Arts" (encompassing 23 Subjects), and "Graphic Arts, Drawing, Design" (encompassing nine Subjects), both of which fall within the Division 'Art and Architecture'. At the time of the data collection the "Decorative Arts, Applied Arts" collection consisted of 7426 titles, and "Graphic Arts, Drawing, Design" collection consisted of 3493 titles. This total of 10,919 titles represented $2.45 \%$ of the Library's collection of 446,613 items that fell within the parameters set for data collection.

The data parameters were restricted in three ways. Firstly, the commencement date for publication was set to 1800, although Collection Analysis will retrieve publication dates back to a category "pre-1500". The commencement of 1800 was chosen because the number of publications with dates prior to this was understandably small, and a review of these records indicated that an unacceptably high number were the result of data input error. Secondly, 
Collection Analysis also has a category "Other" for items with no recorded date. These were again comparatively small and were omitted from the data collection. Thirdly, Collection Analysis provides for some 26 publication types, many designating electronic and microforms. For this exercise only the category "Books" was selected, as the focus of the study is on the possibility of creating a repository collection of printed monographs.

The Collection Analysis software makes it possible to analyse the collection of a single library according to the level of detail required (for example, by Division, Category or Subject). A key feature of Collection Analysis, however, is that it also enables a library's holdings to be easily compared to those of other libraries with data in WorldCat. These comparisons can be conducted between the requesting library and another single library, or between the requesting library and a "group" of up to ten libraries created for the purpose.

For this current exercise it was decided to undertake a comparison of the RMIT holdings for the discipline Design with the holdings of two groups of libraries. As the purpose of the exercise was to assess the potential for the RMIT Library to serve as a collection of first resort for the discipline of Design in Victoria, both of these groups were comprised of Victorian libraries only.

The first group (VAL) consisted of seven Victorian academic libraries serving the following Universities: Ballarat, Deakin, La Trobe, Melbourne, Monash, Swinburne, Victoria. Several of these universities support courses and research in Design: the University of Melbourne has a School of Design; Monash University a Faculty of Art, Design and Architecture; Latrobe University offers a Bachelor of Graphic Design; and Victoria University provides Diploma level qualifications in Graphic Design.

The second group (ART) included three Melbourne-based libraries considered likely to have strong collections in Design. This group consisted of the State Library of Victoria and the libraries serving the Museum of Victoria and the National Gallery of Victoria.

\section{Results}

Data collection was undertaken on January $21^{\text {st }} 2013$, so all figures reflect the WorldCat records at that date.

Table 1 reports the Design holdings for RMIT and the two library groups, post-1880, presented according to date of publication.

Table 1: Design holdings by publication date: RMIT compared to VAL and ART

\begin{tabular}{|l|c|c|c|c|c|c|c|c|c|c|}
\hline & $\begin{array}{l}1800- \\
1899\end{array}$ & $\begin{array}{l}1900- \\
1949\end{array}$ & $\begin{array}{l}1950- \\
1959\end{array}$ & $\begin{array}{l}1960- \\
1969\end{array}$ & $\begin{array}{l}1970- \\
1979\end{array}$ & $\begin{array}{l}1980- \\
1989\end{array}$ & $\begin{array}{l}1990- \\
1999\end{array}$ & $\begin{array}{l}2000- \\
2010\end{array}$ & $\begin{array}{l}2011 \\
- \\
2012\end{array}$ & Total \\
\hline RMIT & 21 & 111 & 153 & 505 & 1343 & 1507 & 2013 & 4574 & 692 & 10,919 \\
$\%$ & 4.0 & 4.2 & 10.5 & 14.9 & 18.5 & 15.4 & 19.8 & 30.4 & 41.9 & 30.0 \\
\hline VAL & 324 & 1413 & 755 & 1626 & 3413 & 5276 & 5243 & 7739 & 700 & 26489 \\
$\%$ & 62.0 & 53.5 & 52.0 & 47.9 & 46.9 & 53.8 & 51.5 & 51.4 & 42.5 & 50.9 \\
\hline ART & 178 & 1118 & 543 & 1265 & 2516 & 3026 & 2933 & 2751 & 260 & 14,590 \\
\hline
\end{tabular}




\begin{tabular}{|l|c|c|c|c|c|c|c|c|c|c|}
\hline$\%$ & 34.0 & 42.3 & 37.4 & 37.2 & 34.6 & 30.8 & 28.8 & 18.3 & 15.7 & 28.1 \\
\hline Total & 523 & 2642 & 1451 & 3396 & 7272 & 9809 & 10,189 & 15,064 & 1652 & 51,998 \\
\hline
\end{tabular}

It is noticeable that the data in Table 1 indicates that the rate of acquisitions of printed books in Design continues to increase, particularly for RMIT and VAL. While it might be the case that Design is a discipline that continues to value printed material, this result is nonetheless far from indicating a decline in printed books and points to the reason for the continued demand for new storage space in the absence of a corresponding number of withdrawals.

The data also indicates the strength in the recent rate of growth in the RMIT collection as compared to both the VAL and ART collections, a trend that has been particularly evident since at least the 1990s. Although the figures for 2011-2012 are necessarily preliminary, they suggest that the number of Design titles acquired by RMIT may be approaching the level of the other seven university libraries combined.

There is also an indication of the decline in the rate of growth in the ART libraries. This is true in both comparative terms (from a high of $37.4 \%$ in 1950-1959) and absolute terms (from a high of 3026 titles in 1980-1989).

The Collection Analysis software also allows a calculation of the level of uniqueness and overlap when comparing a library's collection against that of either a single library or a group of libraries. In this case a uniqueness/overlap comparison was undertaken between the RMIT and VAL collections.

Table 2: Design unique titles and overlap: RMIT compared to VAL

\begin{tabular}{|l|c|c|c|}
\hline & Total & Unique & Overlap \\
\hline RMIT & 10,919 & 4326 & 6593 \\
$\%$ & & 39.6 & 60.4 \\
\hline VAL & 26,489 & 19,896 & 6593 \\
$\%$ & & 75.1 & 24.9 \\
\hline
\end{tabular}

The total number of different Design titles held by RMIT and VAL is 30,815 (4326 + 19,896 $+6593)$.

The data indicates that $39.6 \%$ (4326) of the RMIT collection consists of unique titles when compared to VAL, and RMIT includes $24.9 \%$ (6593) of the titles held by the other seven university libraries. While there are no predictable or desirable levels of overlap between library collections there is some evidence to indicate that there will be variations between disciplines with a comparatively high incidence of uniqueness within the "Art and Architecture" Conspectus division (Genoni and Wright, 2011). It is, however, a result that indicates that at the very least the RMIT Design collection already adds considerably to the corpus of material on the discipline available in Melbourne or wider Victoria. Despite other libraries represented in VAL providing collections for teaching and research in the discipline, 
nearly $40 \%$ of titles in the RMIT collection remain unique amongst Victorian academic libraries.

The Collection Analysis software also enables a closer examination of the overlap within a comparison group, in this case VAL. Table 3 accounts for the number of titles held by one or more VAL libraries, while also indicating the number of titles in each category that overlap with RMIT.

Table 3: Design overlap expanded: RMIT compared to VAL

\begin{tabular}{|c|c|c|c|c|}
\hline Held by & $\begin{array}{c}\text { Total held by } \\
\text { VAL }\end{array}$ & $\begin{array}{c}\text { Unique to } \\
\text { VAL }\end{array}$ & $\begin{array}{c}\text { Overlap titles } \\
\text { with RMIT }\end{array}$ & $\begin{array}{c}\text { Duplicate } \\
\text { copies }\end{array}$ \\
\hline 1 & 18,184 & 15,358 & 2826 & 2826 \\
\hline 2 & 4966 & 3180 & 1786 & 3572 \\
\hline 3 & 2024 & 958 & 1066 & 3198 \\
\hline 4 & 897 & 303 & 594 & 2380 \\
\hline 5 & 295 & 78 & 217 & 1085 \\
\hline 6 & 99 & 17 & 82 & 492 \\
\hline 7 & 24 & 2 & 22 & 154 \\
\hline Total & 26,489 & 19,896 & 6593 & 13,707 \\
\hline
\end{tabular}

One outcome of this level of overlap analysis is that it provides data about the number of titles (although not volumes) that could potentially be withdrawn from collections if participating libraries chose to do so on the basis that one library would undertake the role of a repository by committing to permanent retention. The 6593 overlapped titles are represented in the VAL collections by 13,707 copies that overlap with RMIT. In contrast, the total number of titles held in a single copy only by either RMIT or VAL is 19,684 (4326 Unique to RMIT $+15,358$ Unique to VAL and not duplicated within VAL). This means that $63.9 \%(19,684$ / 30,815) of Design titles held by the eight libraries (RMIT + VAL) are held in a single copy only.

These figures do not, of course, imply that all libraries would be willing to de-duplicate collections irrespective of the role that one other library might assume with regard to retaining print items. Local needs will frequently require local storage. Therefore on the assumption that older material may be more likely to be discarded, a report was also obtained to cover the years 1800-1999. (This assumption is supported by an examination of the Design collection held by the CARM Collection-consisting of items deposited by Victorian academic libraries - which contains only one of 422 items published post-1999.)

Table 4: Design overlap expanded: RMIT compared to VAL, 1800-1999

\begin{tabular}{|c|c|c|c|c|}
\hline Held by & $\begin{array}{c}\text { Total held by } \\
\text { VAL }\end{array}$ & $\begin{array}{c}\text { Unique to } \\
\text { VAL }\end{array}$ & $\begin{array}{c}\text { Overlap titles } \\
\text { with RMIT }\end{array}$ & $\begin{array}{c}\text { Duplicate } \\
\text { copies }\end{array}$ \\
\hline 1 & 12,390 & 11,307 & 1353 & 1353 \\
\hline 2 & 3314 & 2381 & 933 & 1866 \\
\hline 3 & 1390 & 749 & 641 & 1923 \\
\hline 4 & 617 & 224 & 393 & 1572 \\
\hline
\end{tabular}




\begin{tabular}{|c|c|c|c|c|}
\hline 5 & 241 & 66 & 175 & 875 \\
\hline 6 & 79 & 12 & 67 & 402 \\
\hline 7 & 19 & 2 & 17 & 119 \\
\hline Total & 18,050 & 14,471 & 3579 & 8110 \\
\hline
\end{tabular}

Table 4 indicates that even when limited to older items there is still considerable scope for deduplication, with a total of 3579 overlapped titles being represented by 8110 copies in the VAL collections.

A uniqueness and overlap comparison was also undertaken between the RMIT and the three non-academic collections grouped as ART.

Table 5: Design unique titles and overlap: RMIT compared to ART

\begin{tabular}{|l|c|c|c|}
\hline & Total & Unique & Overlap \\
\hline RMIT & 10,919 & 7921 & 2998 \\
$\%$ & & 72.5 & 27.5 \\
\hline ART & 14,590 & 11,592 & 2998 \\
$\%$ & & 79.4 & 20.6 \\
\hline
\end{tabular}

When compared to the smaller ART collection the unique items in RMIT rises to $72.5 \%$ (7921), with $20.6 \%$ (2998) of items in the ART collection also held by RMIT. The number of different titles held by RMIT and ART is 22,511.

Table 6: Design overlap expanded: RMIT compared to ART

\begin{tabular}{|c|c|c|c|c|}
\hline Held by & $\begin{array}{c}\text { Total held by } \\
\text { ART }\end{array}$ & $\begin{array}{c}\text { Unique to } \\
\text { ART }\end{array}$ & $\begin{array}{c}\text { Overlap titles } \\
\text { with RMIT }\end{array}$ & $\begin{array}{c}\text { Duplicate } \\
\text { copies }\end{array}$ \\
\hline 1 & 13,152 & 10,676 & 2475 & 2475 \\
\hline 2 & 1377 & 891 & 486 & 972 \\
\hline 3 & 62 & 25 & 37 & 111 \\
\hline Total & 14,590 & 11,592 & 2998 & 3558 \\
\hline
\end{tabular}

The total number of titles held in a single copy only by either RMIT or ART is 18,593 (7921 Unique to RMIT + 10,676 Unique to VAL and not duplicated within VAL), meaning that $82.6 \%$ of titles held by the four libraries (RMIT + ART) are held in a single copy only. This contrasts with the 2998 overlapped titles with a total of 6556 copies (3558 duplicates) shared between RMIT and VAL.

Three other tests were conducted in order to get the best understanding of the distribution of Design holdings. Firstly, it was possible to create a combined "group" of the VAL and ART libraries. This could be done only because the total of the libraries represented in the two groups is ten, the maximum number that is possible using the Collection Analysis software. 
Table 7: Design unique titles and overlap: RMIT compared to VAL+ART

\begin{tabular}{|l|c|c|c|}
\hline & Total & Unique & Overlap \\
\hline RMIT & 10,919 & 3796 & 7123 \\
$\%$ & & 34.8 & 65.2 \\
\hline VAL+ART & 34,014 & 26,891 & 7123 \\
$\%$ & & 79.1 & 20.9 \\
\hline
\end{tabular}

On the basis of this data it is possible to calculate that the total number of different Design titles held by RMIT, VAL and ART combined is 37,810 (3796 + 26,891 + 7123). It is also relevant to note that combining the VAL and ART collections does not substantially affect the level of unique holding for RMIT as that achieved by a comparison to VAL alone (from $39.6 \%$ reduced to $34.8 \%$ ).

From these results for the combined VAL and ART groups it is also possible to calculate the level of uniqueness and overlap experienced between these two groups.

Table 8: Design unique titles and overlap: VAL compared to ART

\begin{tabular}{|l|c|c|c|}
\hline & Total & Unique & Overlap \\
\hline VAL & 26,489 & 19,424 & 7065 \\
$\%$ & & 73.3 & 26.7 \\
\hline ART & 14,590 & 7525 & 7065 \\
$\%$ & & 51.6 & 48.4 \\
\hline
\end{tabular}

Secondly it was decided to conduct comparisons with the two academic libraries in the VAL group that have the largest collections; the University of Melbourne and Monash (note that permission is required from peer libraries in order to conduct one-to-one comparisons).

Table 9: Design holdings by publication date: RMIT compared to University of Melbourne (UM) and Monash University (MON)

\begin{tabular}{|l|c|c|c|c|c|c|c|c|c|c|}
\hline & $1800-$ & $1900-$ & $1950-$ & $1960-$ & $1970-$ & $1980-$ & $1990-$ & $2000-$ & $2011-$ & Total \\
& 1899 & 1949 & 1959 & 1969 & 1979 & 1989 & 1999 & 2010 & 2012 & \\
\hline RMIT & 21 & 111 & 153 & 505 & 1343 & 1507 & 2013 & 4574 & 692 & 10,919 \\
$\%$ & 6.8 & 8.5 & 20.4 & 27.7 & 31.5 & 23.5 & 30.3 & 41.1 & 56.9 & 32.3 \\
\hline UM & 170 & 689 & 397 & 881 & 1741 & 2765 & 2397 & 2306 & 198 & 11,544 \\
$\%$ & 54.8 & 52.7 & 52.9 & 48.6 & 40.9 & 43.1 & 36.1 & 20.7 & 16.3 & 34.1 \\
\hline MON & 119 & 507 & 200 & 436 & 1173 & 2136 & 2227 & 4247 & 325 & 11,370 \\
$\%$ & 38.4 & 38.8 & 26.7 & 23.9 & 27.6 & 33.3 & 33.6 & 38.2 & 26.7 & 33.6 \\
\hline Total & 310 & 1307 & 750 & 1822 & 4257 & 6408 & 6637 & 11127 & 1215 & 33,833 \\
\hline
\end{tabular}

It is apparent from these figures that the three universities have Design collections of a very similar size, despite the overall considerably larger collections of Melbourne $(1,437,010)$ and Monash $(1,262,761)$. The data also reiterates the evidence presented earlier that in recent 
years the RMIT Design collection has grown at a considerably faster rate than that of other academic libraries.

Uniqueness and overlap data was then gathered in order to further compare the collection of RMIT with the University of Melbourne and Monash University.

Table 10: Design unique titles and overlap: RMIT compared to University of Melbourne

\begin{tabular}{|l|c|c|c|}
\hline & Total & Unique & Overlap \\
\hline RMIT & 10,919 & 8017 & 2902 \\
$\%$ & & 73.4 & 26.6 \\
\hline UM & 11,544 & 8642 & 2902 \\
$\%$ & & 74.9 & 25.1 \\
\hline
\end{tabular}

Table 11: Design unique titles and overlap: RMIT compared to Monash University

\begin{tabular}{|l|c|c|c|}
\hline & Total & Unique & Overlap \\
\hline RMIT & 10,919 & 6935 & 3984 \\
$\%$ & & 63.5 & 36.5 \\
\hline MON & 11,370 & 7386 & 3984 \\
$\%$ & & 65.0 & 35.0 \\
\hline
\end{tabular}

These results indicate that RMIT has a higher level of overlap with Monash University as compared to the University of Melbourne. The rate of overlap between the RMIT and the two academic libraries is of a similar order to that observed between RMIT and another collection of broadly similar size, that of the ART group (27.5, see Table 5 above).

Thirdly, the OCLC Collection Analysis software allows for an examination of the details (full WorldCat record) of the individual titles in any result category. It was therefore decided to select a random sample from the 4326 RMIT titles that are not overlapped by the VAL. The purpose of this was to determine how widely held these titles are by other Victorian and Australian libraries. Records retrieved from WorldCat are presented in order according to the number of "Worldwide library holdings". Care was therefore taken-using a random number generator (http://www.random.org) -to ensure that the items included in the sample of 50 had equal chance of being selected from any point in the retrieved list of 4326 . Any title retrieved with five worldwide holdings or less was eliminated from the sample. This was to avoid the possibility of including grey (or non-commercial) literature that would not fall within the collection development parameters of most libraries, such as academic theses completed at RMIT. The lowest number of worldwide holdings recorded for any sampled item was 17.

The 50 records were then checked (using the "Regional holdings" option) for all their Australian holdings records, and counted according to their holdings in Academic libraries (including non-university); Public libraries; National/ State/ Territory libraries; and "Other" (mainly special, but including a small number of school libraries).

Table 12: Australian library holdings of items held by RMIT but not VAL (sample: $n=50$ ) 


\begin{tabular}{|l|c|c|c|c|}
\hline & Academic & Public & National/State & Other \\
\hline No of titles held & 32 & 27 & 30 & 17 \\
\hline No of copies held (c) & 96 & 191 & 61 & 18 \\
\hline Copies per title (c/50) & 1.92 & 3.82 & 1.22 & 0.36 \\
\hline
\end{tabular}

It is a characteristic of Design that there will be a higher incidence of holdings of some titles in public libraries than would be the case for other Conspectus divisions, particularly those in the sciences. Two titles, both on interior decoration and design, accounted for 79 of the 191 copies held in public libraries. Nevertheless the results indicate that for this discipline there is a wide spread of duplication across different types of libraries.

It is also relevant that of the 50 titles sampled, six had no record of Australian holdings other than RMIT, and for an additional eight there were no other Victorian holdings. Therefore for 14 titles (28\%) the RMIT copy is the only copy recorded as being available in a Victorian library. This result suggests that the RMIT Design collection includes a considerable number of items that are unique in Victorian and Australian libraries.

\section{Discussion and conclusion}

Based on the data presented above the following observations can be made:

1. Acquisitions of printed monographs by Victorian academic libraries in the discipline of Design are growing at a faster rate than ever before.

2. RMIT University library is currently the biggest purchaser of Design monographs of the Victorian academic libraries.

3. Based on the trends in the data, coupled with the intention of RMIT University Library to continue to collect intensively in Design, it can be assumed that the Library will soon have the largest collection in Victoria, although lacking the historical depth of the collections held in other libraries.

4. RMIT University Design collection includes a considerable number of items that are unique to Victoria and Australia.

5. Design holdings in Victoria (and Australia) show evidence of being quite evenly distributed across different libraries and different types of libraries.

It can be concluded on the basis of these observations that the Design collection of RMIT University Library forms an important component of the distributed collection in this discipline area. There is some possibility that other libraries could choose to de-duplicate their collections of low use Design material based on the overlap of holdings with RMIT, although this is unlikely in the case of those academic libraries supporting universities that are still actively teaching and researching in this discipline.

It should also be noted that the Design collection in Victoria shows no sign of being unreasonably duplicated. Indicators or expectations with regard to duplication are difficult to establish, and rates of duplication will inevitably be influenced by many local factors and vary between disciplines, but there appear to be no unpredictable or unexpected "spikes" in duplication, based on either group analysis or comparisons between RMIT and other 
individual academic libraries. Previous research (Genoni and Wright, 2011) has indicated the comparatively high level to which collections of libraries in the Australian Technology Network (including RMIT) are overlapped by the collections of the libraries of the research oriented "Group of Eight" universities (including the University of Melbourne and Monash University). This does not, however, appear to be the case with the Design collection with overlap currently at $26.6 \%$ for RMIT and $25.1 \%$ for Melbourne (see Table 10). This is likely to be the case because unlike other disciplines, the Design collections are a similar size due to the very active recent collecting by RMIT. Therefore while it might be conceivable to envisage a situation whereby the duplication between RMIT and the University of Melbourne was actively managed and further reduced given the very close proximity of these two collections, the resources required to achieve this may not be matched by the benefits. Some further research incorporating the circulation rates of duplicated items could reveal the extent to which the current of duplication is justified. The implications from this study are that the users of each library (RMIT and University of Melbourne) would already draw substantial and approximately equal potential benefit from the proximity of the other.

It can be concluded that on the basis of this study that Victoria (and probably by extrapolation, Australia) has already achieved a form of distributed storage (and indeed distributed collection) for the discipline of Design. This is not what could be described - to use the language applied to the DNC - as "fully implemented". That would require more formal agreements regarding long-term or permanent retention, guarantees about the conditions of storage, and commitments to access. As a result the potential savings in terms of storage costs will not be realised, but nevertheless the present arrangement is largely functional and adequately supported by current infrastructure in terms of discovery and delivery.

It is also a circumstance that allows a middle-size academic library such as RMIT to make a significant contribution to national research infrastructure while supporting its own university's teaching and research priorities. One of the concerns about a de facto form of distributed storage is that it would rely heavily on research intensive universities to carry the burden of print storage costs and the beneficiaries would be smaller libraries adopting the comparative low-cost stance of a steady-state collection. The RMIT approach to building and storing a significant Design collection makes them an important contributor to meeting national demand in the discipline.

\section{Acknowledgement}

I would like to thank Dr Craig Anderson and the staff of RMIT University Library for providing and assisting with the use of the OCLC Collection Analysis software to conduct this study.

\section{REFERENCES}

Anderson, Craig. 2013 forthcoming. "Practical overlap: the possibility of replacing p-books with e-books." Australian Academic and Research Libraries. 
Boyle, Frances, and Chris Brown. 2010. "The UK Research Reserve (UKRR): Machinations, Mayhem and Magic.” Interlending \& Document Supply 38(3): 140-146.

CHEMS Consulting. 2005. Optimising Storage and Access in UK Research Libraries: A Study for CURL and the British Library. CHEMS Consulting.

Clement, Susanne K. 2012. "From Collaborative Purchasing Towards Collaborative Discarding: The Evolution of the Shared Print Repository." Collection Management 37(3-4): 153-167.

Genoni, Paul. 2001. "Slouching Towards Calvary: Whereto the National Collection." Australian Academic and Research Libraries 32(2): 69-81.

Genoni, Paul. 2007. "Towards a National Print Repository for Australia: Where from and Where to?" Australian Academic and Research Libraries 38(2): 84-98.

Genoni, Paul. 2008. "Current and Future Print Storage for Australian Academic Libraries: Results of a Survey." Library Collections, Acquisitions \& Technical Services 32(1): 31-41.

Genoni, Paul. 2013 forthcoming. "An International Review of the Development and Implementation of Shared Print Storage." Australian Academic and Research Libraries.

Genoni, Paul, and Jeanette Wright, J. 2010. "Assessing the Collective Wealth of Australian Research Libraries: Measuring Overlap Using WorldCat Collection Analysis." Australian Library Journal 59(4): 197-207.

Genoni, Paul, and Jeanette Wright. 2011. "Australia's National Research Collection: Overlap, Uniqueness and Distribution." Australian Academic and Research Libraries 42(3): 162-178.

Kieft, Robert H., and Lizanne Payne. 2010. "A Nation-Wide Planning Framework for LargeScale Collaboration on Legacy Print Monograph Collections." Collaborative Librarianship 2(4): 229-33.

Kieft, Robert H., and Lizanne Payne. 2012. "Collective Collection: Collective Action." Collection Management 37(3-4): 137-152.

Kieft, Robert H., and Bernard F. Reilly. 2009. "Regional and National Cooperation on Legacy Print Collections.” Collaborative Librarianship 1(3): 106-08.

Lavoie, Brian, Constance Malpas and J. D. Shipengrover. 2012. Print Management at "Mega-scale": A Regional Perspective on Print Book Collections in North America. Dublin, Ohio: OCLC Research. Accessed January 4, 2013.

http://www.oclc.org/research/publications/library/2012/2012-05.pdf.

National and State Libraries Australasia. Distributed Repository Discussion Paper. Accessed January 4, 2013. http://www.nsla.org.au/sites/default/files/publications/NSLA.DiscussionPaper-Distributed.Repository_2010_0.pdf 
Renwick, Helen. 2013 forthcoming. "Preserving Print Collections: The New Zealand University Libraries and Collaborative Storage." Library Management 34(4/5).

Saarti, Jarmo, and Pentti Vattulainen. 2013 forthcoming. "Management of and Access to Print Collections in National and Repository Libraries in Europe: collection for use or for preservation." Library Management 34(4/5).

Shorley, Deborah. 2008. "Past Its Shelve by Date? United Kingdom Research Reserve (UKRR): A Twenty-First-Century Strategy to Protect our Research Information for the Future." New Review of Academic Librarianship 14(1): 115-120.

Vattulainen, Pentii. 2004. "National Print Repository Initiatives in Europe." Library Collections, Acquisitions \& Technical Services 28(1): 39-50.

Wainwright, Eric. 1991. "The Distributed National Collection: A View from the Centre." Australian Library Journal 40: 210-221.

Wright, Janette, Cathie Jilovsky and Craig Anderson. 2012. "The Story of a Shared Last Copy Repository in Australia: The CARM Centre Stage 2 Development." Collection Management 37(3-4): 271-93.

Yang, Daryl. 2013, forthcoming. "UK Research Reserve: A Sustainable Model from Print to E?" Library Management 34(4/5). 